\title{
САНКЦИИ И ПРАВА ЧЕЛОВЕКА: МЕЖДУНАРОДНО-ПРАВОВЫЕ ПРОБЛЕМЫ
}

Калинин А.B.

Выпускник МП факультета МТНМО (У) МИД Россни

Одним из наиболее острых и противоречивых вопросов современного международного права является вопрос о том, каким образом экономические санкции влияют на соблюдение прав человека в государстве, ставшем объектом этих санкций. У данного вопроса есть и другой аспект: в какой мере нарушение прав человека в каком-либо государстве может служить основанием для применения к нему принудительных мер по главе VII Устава ООН, в частности экономических санкций?

В настоящей статье рассматривается главным образом первый вопрос. Во многих отношениях он имеет чисто этический характер. Представляется, однако, что при анализе международноправовых проблем использование моральных и этических критериев вполне уместно. Само становление и развитие международного права в значительной мере связано с закреплением в нем общечеловеческих ценностей и моральных принципов. Нельзя не согласиться с Ю.А. Решетовым и в том, что ничто не способствует общему развитию человечества по восходящей линии в такой мере, как приверженность принципам и нормам международного права. ${ }^{1}$

Принцип всеобщего уважения прав человека прочно закрепился в качестве императивной нормы общего международного права (jus cogens). Если следовать определению, содержащемуся в ст. 53 Венской конвенции о праве международных договоров 1969 r., такая норма "принимается и признается международным сообществом в целом как норма, отклонение от которой недопустимо и которая может быть изменена только последующей нормой общего международного права, носящей такой же характер". ${ }^{2}$ Права человека не являются застывшей, раз и навсегда оформившейся категори- 
ей. Концепции прав человека и их нормативное закрепление развиваются по мере развития представлений о должном положении в этой сфере с учетом реальных возможностей общества его особенностей. Так, в настоящее время речь идет уже о так называемом "третьем поколении" прав, включающем право на развитие. Между тем, существует уже сложившаяся система международных стандартов в области прав человека, на которые должно ориентироваться все международное сообщество.

В то же время принцип уважения прав человека представляет собой один из основных принципов современного международного права, для которых, как известно, характерны неделимость и равенство: они взанмно связаны, каждый из них должен рассматриваться в контексте друтих, ни один из них не является приоритетным по сравнению с другими. Это особенно важно в свете попыток оправдать примененне силы против того или иного государства под предлогом защиты прав человека. Здесь возникает еще один сложный вопрос: как сочетаются принцип защиты прав человека и, с точки зрения воздействия на права человека, исключение из принципа неприменения силы и угрозы силой в случае обращения Совета Безопасности к принудительным мерам в контексте системы коллективной безопасности? Ясно, что оба затрагиваемых вопроса выводят нас на другой широко обсуждаемый в настоящее время принципиальный вопрос о примате прав человека над обязательствами государств по Уставу ООН.

\section{Соблюдение прав человека в условиях санкционного режима}

В случае применення в отношении государства экономических санкций для оценки их воздействия на права человека необходимо проводить четкое различие между частичными и всеобъемлющими санкциями. Совершенно понятно, что последние влекут за собой куда более тяжелые последствия для населения по сравнению, например, с перерывом воздушных сообщений или эмбарго на поставки оружия. 
Кроме того, следует учитывать состояние экономики государства, ставшего объектом санкций, и ес особенности. Чем менше дия экономки страны характерна автаркия, тем более разрушительное воздействие оказывается на ее население. Бывшему Генератному секретарю ООН Б.Бутросу Гали прннадлежат слова: "По общему признанию санкцин являются жестким инструментом. Их применение поднимает этическй вотрос о том, являются ли страдания, причиняемые уязвимым группам в страке, ставшей объектом санпций, законным средством давления на политических руководителен̆, на поведенне которьх вряд ли повлияет тяжелое положение, к которому привели непредвиденные или нежелательные последствия. Они могут ослокнить деятельность гуманитарных учреждений, лишая их возможности осуществлять поставки определенных категорий товаров или вынуждая их проходить через нзнурительный процесс собподения процедур, предусмотренньх дия получения необходимых изљтин". 3 Всеобъемлющие экономические санкцин некзбежко вступают в противоречие с целями развития страны, ставшеи их объектом, не говоря уже о третьих странах, сталкиваюшихся со значтельными эюономнческями трудностямн в связи с участием в осуществленин санкцй. Это также может представлть угрозу миру и безопасности.

Действительно, когда к государствам применяются принудительные меры по главе VII Устава ООН, возникает несоответствие глубинного характера, которое заключается в том, что фактически в конечном счете всегда страдают простые люди, на них тяжелым бременем ложатся последствия необдуманных политических решений и ошибок руководства.

В условиях экономических санкций всеобъемлющего характера, особенно продолжительных, как это имеет место в случае с Ираком, основной ущерб причиняется элементарным правам человека, в первую очередь праву на жизнь, и правам, связанным с нормальным человеческим существованием. Речь идет не о сложных гражданских и политических правах и тем более не о социальных и экономических - речь идет о том, что в условиях всеобъемлющих 
санкций государство не может обеспечить своим гражданам достаточного количества продуктов питания, лекарств, элементарных средств к существованкю.

Государства, являющиеся основными действующими лицами на международной арене, и международное сообщество в целом не могут не предвидеть подобных последствий применения санкций и должны прилагать усилия с тем, чтобы по возможности облегчить тяжелое положение, в котором оказывается население страны - объекта санкций. В случае с Ираком такая попьтка воплотилась в программе "Нефть в обмен на продовольствие". Здесь стоит еще раз повторить, что эта программа не является панацеей от всех бед, она может предложить лишь частичное решение гуманитарных проблем Ирака.

С резкой критикой в адрес затянувшихся санкций в отношении Ирака выступают разного рода неправительственные организации, группы активистов, в том числе международные. В качестве примера можно привести опыт так называемой Организации международного прогресса (IPO), периодически выступающей с призывами о снятии санкций с Ирака.

Особый интерес в связи с этим представляет позиция австрийского профессора $Г$. Кехлера, выраженная в его работе "Политика санкций ООН и международное право". ет санкции, но и пытается обосновать, что в новьг условиях, когда существуют развитые концепции прав человека, меры предусмотренные в главе Устава, могут быть оспорены с точки зрения их международно-правовой легитимности, а сама система коллективной безопасности с центральным местом в ней Совета Безопасности, где все решают "великие державы", представляет собой ничто иное как реликт старой системы международного права, которая предопределялась концепцией силы. Интересное и парадоксальное соображение, особенно на фоне попыток со стороны некоторых государств выступать в международных отношениях с позиций силы, осуществляя при этом планы, в которых Совет Безопасности фигурирует далеко не на первом месте. 
Австрийский профессор начинает свою критику с рассмотрения этических аспектов санкций в противовес чисто утилитарным подходам. Он полагает, что экономические санкции представляют собой форму коллективного наказания и не соответствуют приниипу индивидуальной ответственности. Наказание людей, не ответственных за политические решения, по его мнению, сродни актам терроризма. Цель подобных действий - повлиять на правительство путем причинения лишений и страданий населению, что аморально само по себе. Применительно к санкциям $\Gamma$. Кехлер упомннает о там называемой "доктрине двойного эффекта", которая разработана для того, чтобы объяснить этические вопросы, возникающие в ситуациях, когда законная цель может быть достигнута лишь путем причинения вреда другим лицам. Здесь в качестве такой цели вступает поддержание или восстановление международного мира и безопасности, а способом достижения цели становится причинение страданий целому народу. Из этого помимо прочего следует также тот факт, что санкции "могут приводить к результатам, идущим в разрез с самой их целью, порождая вызванное патриотическими чувствами негативное отношенне к международному сообществу в лице Организации Объединенных Наций, объединяя насёление на поддержку руководителей, поведение которых санкции как раз и призваны изменить".

Г. Кехлер высказывает также ряд соображений, касающихся нормативной стороны вопроса. По его мнению, применение всеобъемлющих экономических санкций, которые делаюот невозможным нормальное осуществление прав человека, недопустимо. Нельзя, чтобы Совет Безопасности обладал такой широтой усмотрения, чтобы принимать решения, ведущие к ограничению прав человека, нарушая тем самым предписания Устава. Нельзя, чтобы этот орган в его сегодняшнем виде, да и вообще любой политический орган ставил себя выше обшеобязательных норм международното права.

Применение всеобъемлющих санкций, считает Г. Кехлер, противоречит целому ряду международных договоров в области прав че- 
ловека. В частности, он указывает на ст. 25(1) Всеобщей декларащии прав человека, согласно которой "каждый человек имеет право на такой жизненный уровень, включая пицу, одежду, жилище, медицинский уход... который необходим для поддержания здоровья и благосостояния его самого и его семьи...". Далее, впрочем, он вынужден признать, что в упомянутых документах содержатся оговорки, которые не позволаот применять их к случаям обрашения Совета Безопасности к мерам для поддержания и восстановления международного мира и безопасности. Так, ст. 29 (3) Всеобцей декларации гласит: "Осуществление... прав и свобод ни в коем случае не должно противоречить целям и принципам Организации Объединенньх Наций". С учетом п. 1 ст. 1 Устава ООН и отсутствия прямого указания в статье 2 Устава на принцип уважения прав человека можно сделать вывод о "нормативном приоритете" решений Совета Безопасности при осуществлении ответственности, возложенной на него ст. 24 Устава, даже в вопросе прав человека. Кроме того, ст. 103 Устава устанавливает приоритет обязательств государств по Уставу по отношению $k$ иным их обязательствам в соответствии с международным правом. Отмечая это, Кехлер высказывается в том смысле, что указанные оговорки не отражают должного положения вещей в данной сфере, они - проявление критикуемой им системы коллективной безопасности в том виде, в каком она закреплена в Уставе ООН.

Профессор Г. Кехлер пытается также применить к экономическим санкциям нормы международного гуманитарного права. $\mathrm{OH}$ признает, что в строгом смысле они неприменимы к мерам, предпринимаемым Советом Безопасности по главе VII, но пытается обосновать их применение тем, что санкции фактически представляют собой средство ведения войны. В связи с этим Кехлер упоминает ст. 541 Дополнительного протокола к Женевским конвенциям. согласно которой "залрещается использовать голод среди гражданского населения в качестве метода ведения войны", ссылается на оговорку Мартенса. По его мнению, то, что применимо в случае вооруженного конфликта, тем более должно применяться к осуществ- 
лению принудительных мер экономического характера (по аналогии), в противном случае ведение войны отвечало бы более высоким критериям справедливости и гуманности по сравнению с применением экономических санкций. Это умозаключение носит, как представляется, сомнительный характер, но в то же время позволяет сделать вывод о весьма негативном отношении профессора к всеобъемлющим экономическим санкциям.'

С Г. Кехлером нельзя не согласиться в том, что желательно по возможности избегать обращения к всеобъемлющим санкциям как наиболее жесткому механизму обеспечения решений Совета Безопасности. В случае же их применения необходимо следить за тем, чтобы они сами не поставили население страны - объекта в катастрофическое положение, как это случилось с Ираком. В особенности это касается слабозащищенньх групп населения - детей, женщин и престарельх.

Вместе с тем совершенно очевидно, что острие его критики направлено на нормативную систему международного права в целом и концепцию коллективной безопасности в частности. Разумеется, такая критика не только допустима, но и во многом полезна современное международное право не представляет собой совершенную, окончательно сложившуюся и застывшую систему. Однако всегда стоит следить за тем, чтобы такая критика не приобрела характер reductio ad absurdum.

В настоящее время не приходится говорить о примате прав человека в качестве общепризнанной нормы международного права, которая служила бы критерием международно-правовой легитимности действий, предпринимаемых государствами или их группами. Известный нам принцип всеобщего уважения прав человека адресован государствам, которые должны стремиться к тому, чтобы в пределах своей национальной юрисдикции обеспечивать последовательное претворение в жизнь существующих международных стандартов в области прав человека. Речь пока не идет о том, чтобы придать этому принципу характер јus super cogente. 
Проблемы, на которые указывает профессор Г. Кехлер, могут быть решены в рамках существующих механизмов, в том числе путем их адаптации к новым идеям и реалиям международной жизни.

\section{Нарушение прав человека как основание применения} прннуднтельных мер по главе VII Устава ОOH

В случае с Ираком вопрос о возможности применения принудительных мер по главе VII Устава к государству, нарушающему права человека, не носит чисто теоретического характера. США часто ссылаются на грубые и массовые нарушения прав человека в Ираке как на основание, не позволяющее говорить о смягчении или отмене санкций. Правительство Ирака, заявляя о том, что санкции нарушают права человека, всякий раз оказывается в неоднозначном положении, поскольку подобные заявления приводят, как правило, к ответной волне обвинений в адрес иракского правительства в том, что оно само грубо нарушает права человека.

В марте 1991 г., сразу по окончании военной операции "Буря в пустыне", Комиссия ООН по правам человека назначила двух специальных докладчиков: одного для расследования грубых и массовых нарушений прав человека со стороны вооруженных сил Ирака во время оккупации Кувейта, и другого для тщательного изучения нарушения прав человека со стороны иракских властей в самом Ираке. Комиссия была обеспокоена тем, что в Ираке после его поражения в войне участились случаи применения репрессивных мер к тем, кто проявлял недовольство режимом. В особенности это затронуло меньшинства курдов на севере Ирака и шиитов на юге.

Внутренние конфликты в послевоенном Ираке спровоцировали огромный поток беженцев. По официальной информации ООН, за три недели (март-апрель 1991 г.) более 400 тыс. иракцев переместились к граннце с Турцией, а к середине мая приблизительно 1,5 млн. человек (!) нашли убежище в восточной приграничной части Ирака и в Иране. За исключением 70 тыс. шиитов из южных районов, подавляющее большинство составили курды. ${ }^{10}$ Совет Безопасности в резо- 
люции 688 от 5 апреля 1991 г. осудил проводимые иракскими властями репрессии в отношении гражданского населения в различных частях Ирака, главным образом в районах, заселенных курдами. Совет Безопасности отметил, что последствия этих репрессий угрожают международному миру и безопасности и потребовал от Ирака прекратить подобные действия и незамедлительно представить международным гуманитарньм организациям доступ ко всем нуждающимся в помощи в различньх частях страны, а также обеспечить все необходимые для оказания такой помощи средства. ${ }^{11}$

Как следует из докладов, представляемых на регулярной основе Комиссии ООН по правам человека спецдокладчиком по Ираку, с достоверностью установлено наличие в Ираке серьезных нарушений прав человека гражданского и политического, экономического, социального и культурного характера. В частности, нарушается право на свободу и личную неприкосновенность, имеют место произвольные аресты и задержания, применяются пытки, суд не является независимым, серьезно ограничены права на свободу перемещения и выбора места жительства, свободу мысли, совести и религии, свободу мирных собраний и ассоциации, проводится дискриминация по признаку принадлежности к национальным меньшинствам.

По утверждению спецдокладчика, главной причиной такого положения является характер и структура политической власти в Ираке. В частности, указывается на концентрацию огромных властных полномочий, бесконтрольно осуществляемых небольшой группой лиц во главе с президентом Саддамом Хусейном, который одновременно является премьер-министром, председателем Совета революционного командования и главой Регионального руководства партии Баас (Партия арабского социалистического возрождения). ${ }^{12}$ Аналогичное мнение высказывается в ежегодных докладах о ситуации в области прав человека, подготавливаемых Государственным Департаментом США. ${ }^{13}$

К настоящему времени сложилось достаточно четкое представление о том, что массовые и грубые нарушения прав человека 
исключают ссылку на принцип невмешательства во внутренние дела государств. Практика Совета Безопасности свидетельствует о том, что этот орган ООН рассматривает случаи массового и грубого нарушения прав человека в том или ином государстве в качестве угрозы миру и безопасности. Применяя в таких случаях меры, предусмотренные главой VII Устава, Совет Безопасности действует в полном соответствин с пункт. 7 ст. 2 Устава. Впрочем, всякий раз возникает вопрос о том, является ли адекватным способом разрешения проблемы нспользование силы.

Массовое и грубое нарушение прав человека, проистекающее из общей политической и правовой ситуации в государстве и свидетельствующее о том, что посударство итнорирует свои обязательства уважать права человека, означает нарушение принципа уважения прав человека этим государством. Это, однако, ни в коей мере не может служить оправданием односторонних действий государства или группы государств под прикрытием концепции "гуманитарной интервенции". Сейчас, когда предпринимаются попытки возродить эту концепцию, необходимо четко осознавать опасность ее универсализации. Силовые меры в отношении тех или иных государств в нормативной системе современного международного права могут обладать международно-правовой легитимностью только в том случае, когда они применяются в соответствии с Уставом ООН с санкции Совета Безопасности и под его строгим контролем.

В этом контексте следует затронуть вопрос об установлении в Ираке так называемых "бесполетных зон", которые предусматривают запрет на совершение иракской гражданской и военной авиацией полетов к северу от 36-й параллели и к югу от 33-й. Нарушение этого режима предполагает возможность применения силы против воздушного судна-нарушителя. Контроль за соблюдением режима осуществляет главным образом авиация CША и Великобритании.

В качестве правового обоснования установления таких зон США ссылаются на уже упомянутую резолюцию 688 Совета Безопасности и указывают на необходимость защиты гражданского на- 
селения Ирака, в первую очередь курдов (на севере) и шиитов (на юге), от притеснений со стороны иракского режима. Кроме того, как заявляют американцы, зоны были необходимы для нормального осуществления гуманитарных операций в связи с возросшим потоком беженцев. Между тем, анализ резолюции 688 не позволяет говорить о возможности силовых акций для ее осуществления. Совет Безопасности не уполномочивал ни одно из государств предпринимать меры для принудительного исполнения резолюции 688, тем более в форме установления "бесполетных зон". Это даже не подразумевалось. Напротив, подобные предписания противоречили бы целям самой резолюции и вообще целям, которые преследует Совет Безопасности в послекризисном урегулированин в регионе. В преамбуле резолюции подтверждается приверженность государствчленов ООН уважению суверенитета, территориальной целостности и политической независимости Ирака, в то время как действия США в "бесполетных зонах" под предлогом защиты гражданского населения являются прямым нарушением этих принципов.

Установление "бесполетных зон" на севере и юге Ирака представляет собой одностороннюю и произвольную акщню США, оно не санкционировано Советом Безопасности - единсттвенным органом, который может принимать решения о применении силы с целью поддержания международного мира и безопасности. Такой позиции придерживаются Россия и Китай. Франция в 1996 г. приостановила свое участие в действиях, не обоснованных с точки зрения международного права. Ирак справедливо считает, что в соответствии с Уставом ООН он может использовать право на самооборону против "продолжающегося агрессивного акта" со стороны США и Великобритании, которые свонми односторонними действиями подрывают международный правопорядок, дискредитируют ООН и ослабляют позиции современного международного права ${ }^{14}$. 
1 Ю.А. Решетов. В защиту международного права. // Московский журнал международного права. 1998, № 2, с. 16.

2 Действуюшее международное право (Сборник документов в трех томах). Т. I. М., 1996, c. 359-360.

3 Б. Бутрос Гали. Повестка дня для мира. 1995. Нью-Йорк, 1995, с. 43.

4 Appeal against sanctions addressed to the United Nations Commission on Human Rights. Geneva, 15 August, 1996.

5 Hans Koechler. The United Nations Sanctions Policy and International Law. Kuala Lumpur, 1995.

6 Б. Бутрос Гали. Повестка дня для мира. 1995. Нью-Йорк, с. 43.

7 Всеобщая декларашия прав человека. Декларация прав и свобод человека и гражданина. М., 1993, с. 12.

8 Всеобщая декларащия прав человека. Декларация прав человека и гражданина. M., 1993, c. 14.

9 См. также. Geoffrey Leslie Simons. Imposing Economic Sanctions: Legal Remedy or Genocidal Tool? L.. 1999.

10 The United Nations and the Iraq-Kuwait Conflict, p. 57

11 S/RES/688 (1991) 5 April 1991 - The United Nations and the Iraq-Kuwait Conflict, p. 199.

12 E/CN.4/1995/56, 15 February 1995. Report on the situation of human rights in Iraq submitted by Max van der Stoel, Special Rapporteur of the Commision on Human Rights.

13 U.S. Department of State: Iraq Report on Human Rights Practice for 1996 (released by Bereau of democracy, Human Rights and Labor, January 30, 1997).

14 Letter dated 15 January 1999 from the Permanent Representative of Iraq to the United Nations addressed to the President of the Security Council. 